\title{
Student-Based Morning Report:An Experience at the Internal Medicine Ward
}

\author{
Raika Jamali ${ }^{1,2, *}$ \\ ${ }^{1}$ Students' Scientific Research Center, Tehran University of Medical Sciences, Tehran, IR Iran \\ 2 Research Development Center, Sina Hospital, Tehran University of Medical Sciences, Tehran, IR Iran \\ ${ }^{*}$ Corresponding author: Raika Jamali, Research Development Center Sina hospital, Students Scientific Research Center, Tehran University of Medical Sciences, Tehran, IR Iran. Tel: \\ +98-2163120000, Fax:+98-2163120001, E-mail: jamalira@tums.ac.ir.
}

Received: March 20, 2013; Revised: March 20, 2013; Accepted: April 03, 2013

Keywords: Students, Medical; Curriculum; Internal Medicine

Morning report was initially performed at non-educational hospitals. The on-service nurse and medical staff reported the problems enfaced for the management of patients of the previous working day to the head of ward (1). The aim of this program was modified in teaching hospitals (2). Thereby, morning report is now considered as one of the key elements in medical students' training curriculum. A variety of educational groups participate in morning report; however, residents are the main target population (3). Residents carry on the session and discuss the difficulties in the diagnosis and management of patients (4).

Routinely, the medical students are not actively involved in the program and they usually get bored. Sometimes the scientific level of discussed issue is so high that they cannot follow the conference. To overcome this shortcoming, medical student-based morning report was designed at internal medicine ward of Sina hospital, affiliated to Tehran University of Medical Sciences. During the student-based morning reports, the on-service senior medical students and residents help the juniors to complete their report before the session. Afterward, the junior medical students present the cases in front of a panel that consists of senior medical students and a resident. Accordingly, senior medical students ask questions about the ambiguous issues in the presentation and clarify the pitfalls of junior students' presentations. The resident is the leader of the panel and handles the coordination of the team. We implemented a new role for the residents in this especially designed program that is known as 'resident as a teacher' (5). The attending professor facilitates the process at each step.

A survey on this program showed that it has a progressive character. In fact, the drawbacks in data collection were the major findings in sessions at the beginning of the semester. Comments on how to take a precise report from the patient halted the program at this stage. Medical students were prepared for entering to the next step through resolving the problems with regard to a more accurate history taking. Next step was to make decisions and express the differential diagnosis. Through this step, they were prepared for clinical reasoning and presenting the diagnosis plan later in the semester. The result of this survey also showed that the students were satisfied with the program. The participants' level of self-esteem in oral case presentation, independent decision-making ability, and clinical reasoning was improved after participating in this program.

\section{Financial Disclosure}

No benefits in any form have been received or will be received from a commercial party related directly or indirectly to the subject of this article.

\section{References}

1. Parrino TA. The social transformation of medical morning report. J Gen Intern Med.1997;12(5):332-3.

2. West CP, Kolars JC, Eggert CH, Kennedy CC, Ficalora RD. Changing morning report: evaluation of a transition to an interactive mixed-learner format in an internal medicine residency program. Teach Learn Med. 2006;18(4):330-5.

3. Fassett RG, Bollipo SJ. Morning report: an Australian experience. Med J Aust. 2006;184(4):159-61.

4. Layne K, Nabeebaccus A, Fok H, Lams B, Thomas S, Kinirons M. Modernising morning report: innovation in teaching and learning. Clin Teach. $2010 ; 7(2): 77-82$.

5. Luciano GL, Carter BL, Garb JL, Rothberg MB. Residents-as-teachers: implementing a toolkit in morning report to redefine resident roles. Teach Learn Med. 2011;23(4):316-23. 